\title{
Evolutionary Characterization of Human H1N1 Influenza Virus Hemagglutinin Genes Isolated from 1947 to 2009 in China
}

\author{
She-Lan Liu ${ }^{a}$ Zhiruo Zhang ${ }^{b}$ Chengmin Wang ${ }^{f}$ Ying Dong $^{c}$ Hao Pan ${ }^{d}$ \\ Zhou Sun $^{a}$ Xun-hui Yang ${ }^{a}$ Jing Wang ${ }^{a}$ Bing Ruan ${ }^{\mathrm{e}}$ Li Xie $^{\mathrm{a}}$ Jing Deng ${ }^{\text {a }}$ \\ Hong-Xuan $\mathrm{He}^{f}$ \\ a Department of Infectious Diseases, Hangzhou Center for Disease Control and Prevention, Hangzhou, \\ ${ }^{b}$ Department of Health Policy Research, School of Public Health, Shanghai Jiao Tong University, Shanghai, \\ 'Department of Oncology, the Second Affiliated Hospital of Zhejiang University School of Medicine, Hangzhou, \\ ${ }^{\mathrm{d}}$ Department of Infectious Diseases, Shanghai Municipal Center for Disease Control and Prevention, Shanghai, \\ e State Key Laboratory for Diagnosis and Treatment of Infectious Diseases, The First Affiliated Hospital, College of \\ Medicine, Zhejiang University, Hangzhou, and ${ }^{\mathrm{f}}$ National Research Center for Wildlife-Borne Diseases, Key Laboratory \\ of Animal Ecology and Conservation Biology, Institute of Zoology, Chinese Academy of Sciences, Beijing, China
}

\section{Key Words}

Influenza H1N1 • Evolutionary characterization •

Hemagglutinin gene

\begin{abstract}
Objective: Our aim was to reveal the molecular characteristics of human H1N1 influenza virus hemagglutinin (HA) genes from 1947 to 2009 in China. Methods: 129 HA gene sequences were downloaded from NCBI's GenBank and analyzed by DNASTAR software. Additionally, the three-dimensional structure of HA protein was predicted by the SWISSMODEL service. Results: First, 2009 Chinese HA genes were 99\% identical to those of Mexican and American ones; their key sites remained highly conserved. Second, 50 Chinese strains from 1947 to 2009 clustered by the year of isolation, and 2009 strains had only $70 \%$ identity to $1947-2008$ ones. Third, over the past 60 years, 3 receptor-binding (RB) sites and 2 of the 8 glycosylation sites (amino acids 279 and 290) underwent considerable changes while the cleavage sites remained stable. Fourth, the human HA sequences differed completely from swine and avian isolates. Finally, the muta-
\end{abstract}

tion of cleavage sites can change the three-dimensional structures, but single mutations cannot. Conclusions: Thus, in the past 60 years, Chinese H1N1 influenza HA genes kept stable with high affinity and low pathogenicity to human except changes in 2 glycosylation and 3 RB sites which were associated with the pandemic strength, range and host specificity of viruses.

Copyright $\odot 2011$ S. Karger AG, Basel

\section{Introduction}

Influenza virus types $\mathrm{A}, \mathrm{B}$, and $\mathrm{C}$ belongs to the family Orthomyxoviridae. Influenza A viruses have been isolated from many species, including humans, pigs, horses, mink, marine mammals and a wide variety of domestic and wild birds. Thus far, they have been classified into 16 hemagglutinin (HA) and 9 neuraminidase (NA) subtypes

\section{S.-L.L., Z.Z. and C.W. contributed equally to this work.}


on the basis of the antigenic properties of $\mathrm{HA}$ and NA that are exhibited on the viral surface [1]. H1N1, H1N2, H2N2, $\mathrm{H} 3 \mathrm{~N} 1, \mathrm{H} 3 \mathrm{~N} 2, \mathrm{H} 5 \mathrm{~N} 1, \mathrm{H} 7 \mathrm{~N} 7$ and $\mathrm{H} 9 \mathrm{~N} 2$ are the main subtypes of influenza A virus that are capable of infecting humans. The most common types of HA gene mutations, which have been responsible for influenza outbreaks, were named 'antigenic shift' and 'antigenic drift'. Over the past 100 years, there have been four pandemic influenza outbreaks: 1918 (Spanish, H1N1), 1957 (Asia, H2N2), 1968 (Hong Kong, H3N2), and 1977 (H1N1).

The 2009 influenza outbreak was caused by a new influenza virus strain, designated H1N1 [2-4]. According to the World Health Organization (WHO) data, as of 1 August, 2010, worldwide more than 214 countries have reported laboratory confirmed cases of pandemic influenza H1N1 2009, including over 18,449 deaths [5]. Reports from China indicated that a total of 127,885 cases including 805 deaths were confirmed by 4 July, 2010 [6]. However, the origin and possible molecular evolution of this new pandemic influenza virus remain unclear.

Here, $129 \mathrm{H} 1 \mathrm{~N} 1$ influenza HA sequences isolated from human, swine and bird between 1947 and 2009 were downloaded from NCBI's Influenza Virus Resource, and analyzed to discover the relationship between viral structure and epidemic features. This will provide benefit to early warning and laboratory diagnosis of influenza H1N1 pandemics.

\section{Materials and Methods}

\section{Influenza H1N1 Strains}

In total, $129 \mathrm{H} 1 \mathrm{~N} 1 \mathrm{HA}$ gene sequences were downloaded from NCBI's Influenza Virus Resource (http://www.ncbi.nlm.nih.gov/ genomes/FLU/FLU.html), including 47 strains from 2009, 50 strains from 1947 to 2009, and 32 strains isolated from 6 human, 22 swine, and 4 avian sources.

\section{Analysis of 129 H1N1 HA Gene Sequences from Three \\ Perspectives}

Phylogenetic Tree Analysis. To study the evolution of the H1N1 HA gene, phylogenetic trees were constructed independently by using DNASTAR software. Alignments were confirmed by visual inspection. Genetic distances were estimated by the six-parameter method, and the trees were constructed using the neighborjoining method. To confirm the reliability of the phylogenetic trees, bootstrap resampling tests were performed 1,000 times.

Amino Acid Sequence Analysis of H1N1 HA. Amino acid sequences of H1N1 HA were deduced from the nucleotide sequences. The receptor-binding (RB), antigenic determinant (AD), glycosylation, and cleavage sites were analyzed using the DNASTAR software program MegAlign. Sequence identity was also determined using the MegAlign program.
Table 1. Amino acid substitutions at potential antigenic sites of H1N1 influenza HA protein isolated from China in 2009

\begin{tabular}{rlr}
\hline Site & $\begin{array}{l}\text { Changes in HA } \\
\text { amino acids }\end{array}$ & Rate of mutation \\
\hline 35 & $\mathrm{~L} \rightarrow>\mathrm{I}$ & \\
103 & $\mathrm{E} \rightarrow \mathrm{G}$ & $4.35 \%(1 / 23)$ \\
144 & $\mathrm{~A} \rightarrow \mathrm{T}$ & $4.35 \%(1 / 23)$ \\
206 & $\mathrm{~S} \rightarrow \mathrm{T}$ & $4.35 \%(1 / 23)$ \\
225 & $\mathrm{D} \rightarrow \mathrm{E}$ & $47.83 \%(11 / 23)$ \\
264 & $\mathrm{~A} \rightarrow \mathrm{V}$ & $4.35 \%(1 / 23)$ \\
296 & $\mathrm{Q} \rightarrow \mathrm{H}$ & $4.35 \%(1 / 23)$ \\
300 & $\mathrm{P} \rightarrow \mathrm{S}$ & $4.35 \%(1 / 23)$ \\
328 & $\mathrm{Q} \rightarrow \mathrm{L}$ & $4.35 \%(1 / 23)$ \\
391 & $\mathrm{~T} \rightarrow \mathrm{I}$ & $4.35 \%(1 / 23)$ \\
394 & $\mathrm{~T} \rightarrow \mathrm{I}$ & $4.35 \%(1 / 23)$ \\
405 & $\mathrm{~K} \rightarrow \mathrm{T}$ & $4.35 \%(1 / 23)$ \\
414 & $\mathrm{~V} \rightarrow \mathrm{I}$ & $4.35 \%(1 / 23)$ \\
458 & $\mathrm{~N} \rightarrow \mathrm{S}$ & $13.04 \%(3 / 23)$ \\
506 & $\mathrm{~V} \rightarrow \mathrm{I}$ & $4.35 \%(1 / 23)$ \\
& & $13.04 \%(3 / 23)$ \\
\hline
\end{tabular}

$\mathrm{HA}=$ Hemagglutinin; $\mathrm{G}=$ gly; $\mathrm{S}=$ ser $\mathrm{A}=$ ala; $\mathrm{T}=$ thr; $\mathrm{V}=$ val; $\mathrm{I}=$ ile; $\mathrm{L}=$ leu; $\mathrm{H}=$ his; $\mathrm{P}=$ pro; $\mathrm{D}=$ asp; $\mathrm{E}=$ glu; $\mathrm{K}=$ lys; $\mathrm{Q}=$ gln; $\mathrm{N}=$ asn.

Prediction of the Three-Dimensional Structure of H1N1 HA. Three protein query sequences, including 2 mutant strains (EU874899) and 2 wild-type strains (GQ183617, GQ225365) isolated in China, were uploaded to the SWISS-MODEL site (http:// swissmodel.expasy.org) and analyzed by six different servers that were used for protein fold recognition or structure prediction (PDB-BLAST, 3D-PSSM, mGenTHREADER, Fugue, SAM-T99, and Jpred). After evaluating the three-dimensional compatibility between the uploaded sequences and the protein templates retrieved from the databank, models were directly constructed using MODELLER with the top-ranking structural alignments [7]. The model numbers were 3FKU, 1RU7, 1RD8, and 1RUY for HA1 and HA2 of EU874899, GQ183617 and GQ225365, respectively. The predicted models were superimposed on the coordinates of the retrieved protein templates by using the Visual Molecular Dynamics (VMD) 1.8.6 software [8-13].

\section{Results}

Comparison of 2009 H1N1 HA Sequences Isolated from China, Mexico, and the USA

We compared $23 \mathrm{H} 1 \mathrm{~N} 1 \mathrm{HA}$ gene sequences isolated from humans in China with 11 from Mexico and 13 from the USA in 2009, and analyzed them by using DNASTAR software. The most common mutation sites and their frequencies in $\mathrm{HA}$ of $\mathrm{H} 1 \mathrm{~N} 1$ isolated in China are listed in table 1. HA protein had 3 RB sites (135-138 VTAA, 190- 


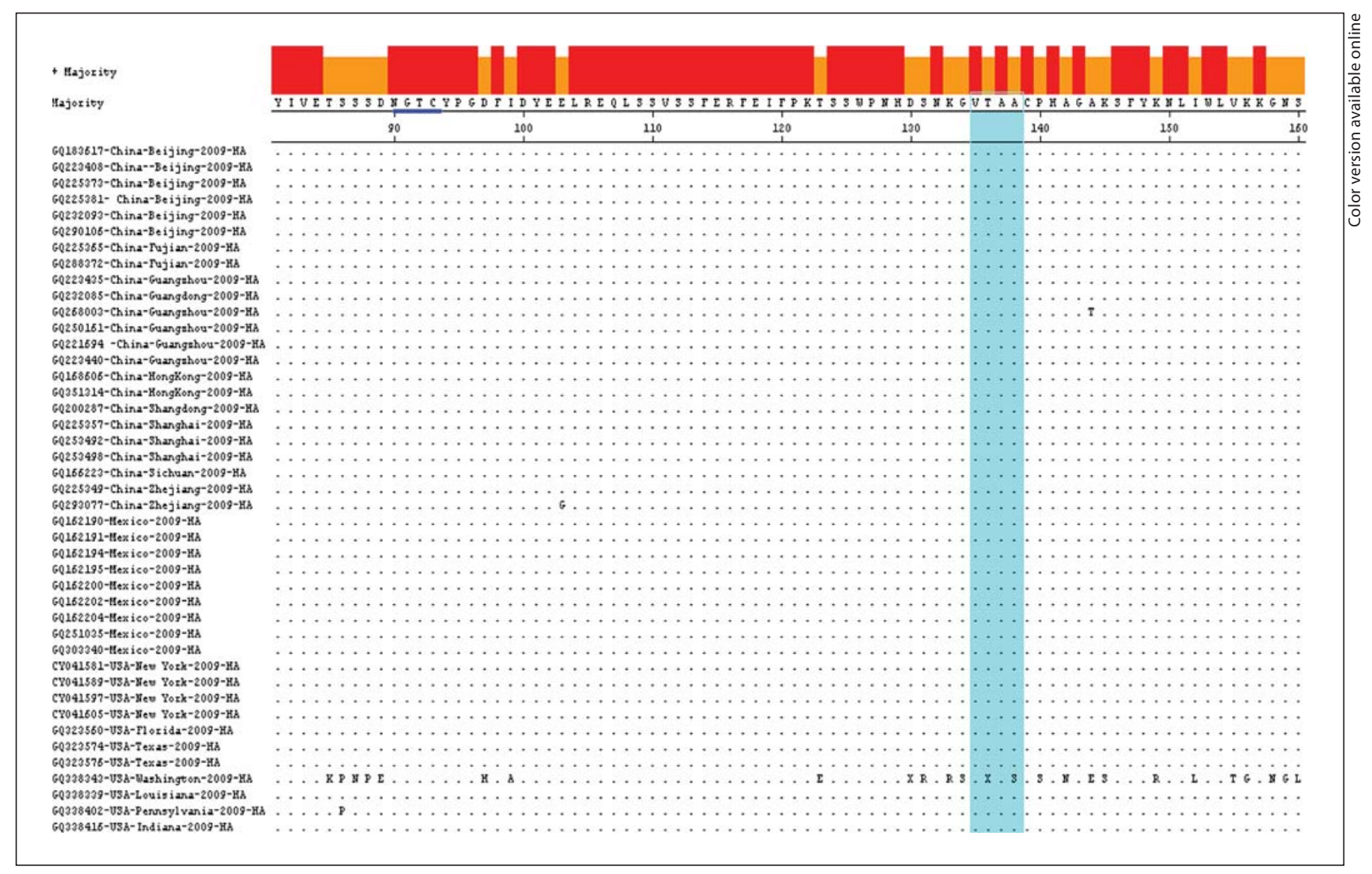

Fig. 1. Comparison of H1N1 influenza HA amino acid isolated from China, Mexico, and the USA in 2009. Blue color '-', potential glycosylation site; green color, HA receptor-binding site; purple color, the cleavage site between HA1 and HA2. Mutation frequencies are represented by the colored blocks at the top of the figures; red colors and higher blocks represent sequences that were con-

198 DQQSLYQNA, and 221-228 PKVRDQEG), 1 cleavage site (325-336, PSIQSRGLFGAI) and 8 glycosylation sites (13N, 14NST, 26NVTA, 90NGTC, 279NTTC, 290NTSL, 484NGTY, and 543NGSL). Amino acid substitutions of all Chinese strains were extremely rare in the 3 RB sites except GQ351314-China-Hongkong-2009-HA showedD $\rightarrow$ Eat aa 225. Similarly, only 1 strain (GQ250161Guangzhou-2009-HA) had a Q $\rightarrow$ L mutation at aa 328 observed in cleavage site. Sequences were conserved in all other strains, and no changes were found in any potential glycosylation sites (fig. 1).

Phylogenetic tree analysis revealed that the HA genes from China, Mexico and the USA constituted the same branch. The evolutionary distances were small. No significant accumulation of geographical characteristics was observed (fig. 2).

Evolutionary Characterization of $\mathrm{H} 1 \mathrm{~N} 1$ Hemagglutinin Genes served, and orange color and shorter blocks represent areas with more divergence. The amino acid name and its position are shown on the second and third line. The strain names downloaded from GenBank are shown on the left. Residues that match the consensus sequence at the top of the figure are represented by ' $'$ '. Colors refer to the online version only. (Figure 1 continues on the next page.)

\section{Molecular Evolution of the H1N1 HA Gene Isolated from Humans in China from 1947 to 2009}

$50 \mathrm{H} 1 \mathrm{~N} 1 \mathrm{HA}$ gene sequences that were isolated from humans in China from 1947 to 2009 were downloaded from GenBank. Phylogenetic tree analysis revealed that the sequences clustered on the basis of their year of isolation. The sequences isolated in 2009 were only $70 \%$ similar to those isolated from 1947 to 2008 and constituted a separate branch (fig. 3).

H1N1 HA mutations from 1947 to 2009 are listed in table 2. H1N1 HA has 8 glycosylation sites. Of these, only 2 sites (aa 279 and aa 290) underwent considerable changes; the other 6 glycosylation sites remained stable and conserved over the past $\sim 60$ years.

During the past 60 years, the RB sites had a lot of changes. For example, the sequences of 135-138 cycle 
+ Hajority

Majority

GQ182617-China-so ijing $-2009-\mathrm{HA}$ 60222408-China--Beijing-2009-HA
G0225373-China-8eijing-2009-HA 60225373-China-seijing-2009-HA
GQ225381- China-Beifing-2009-HA

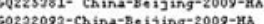

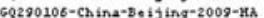
GQ225365-China-rugia 60288372-China-Tuji ian-2009-HA GQ22J405-China-Guangahou-2009-xh Q GQ2000001-China G0221694 -China-Guangzhou-2009-YA $6 Q 223440$-Ch ind-Guangzhou-z00g-KA 60168606-China-Hongkong-2009-KA 60351314-China-Hongkong-2009-KA B0200207-China- Hohangdong-2009GQ225357-China-shanghai-2009-HA
60253492 -China-Shanghai-2009-HA G0253498-China-Shanghai-2009-HB 60166223-Ch ina-3 ichuan-2009-HA GQ225349-China-zhejiang-2009-HA

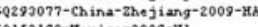
G0162190-Hhx ico-2009-HA G0162194-Hexiso-2008-HA

60162195-Hex ico-2009-HA

$60162200-H$ ex i $<0-2009-$ HA $60162202-\mathrm{Hex}$ ico-2009-HA Goss G0251035-Hexices-2009-14A CW041581-VSA-Bew York-2009-HA CY041589-USA-YHew York-2009-HA Cro41597-V3A-Hew York-2009-HA cosescoso60320080-09A- horida-20096Q7255756-VISA-Texas - 2009 -

6Q350343-U3A-Washington-2009-HA

GQ3ว8ว39-VSA-Louis iana-2009-HA

60238402-V3A-Pensgylvania-200
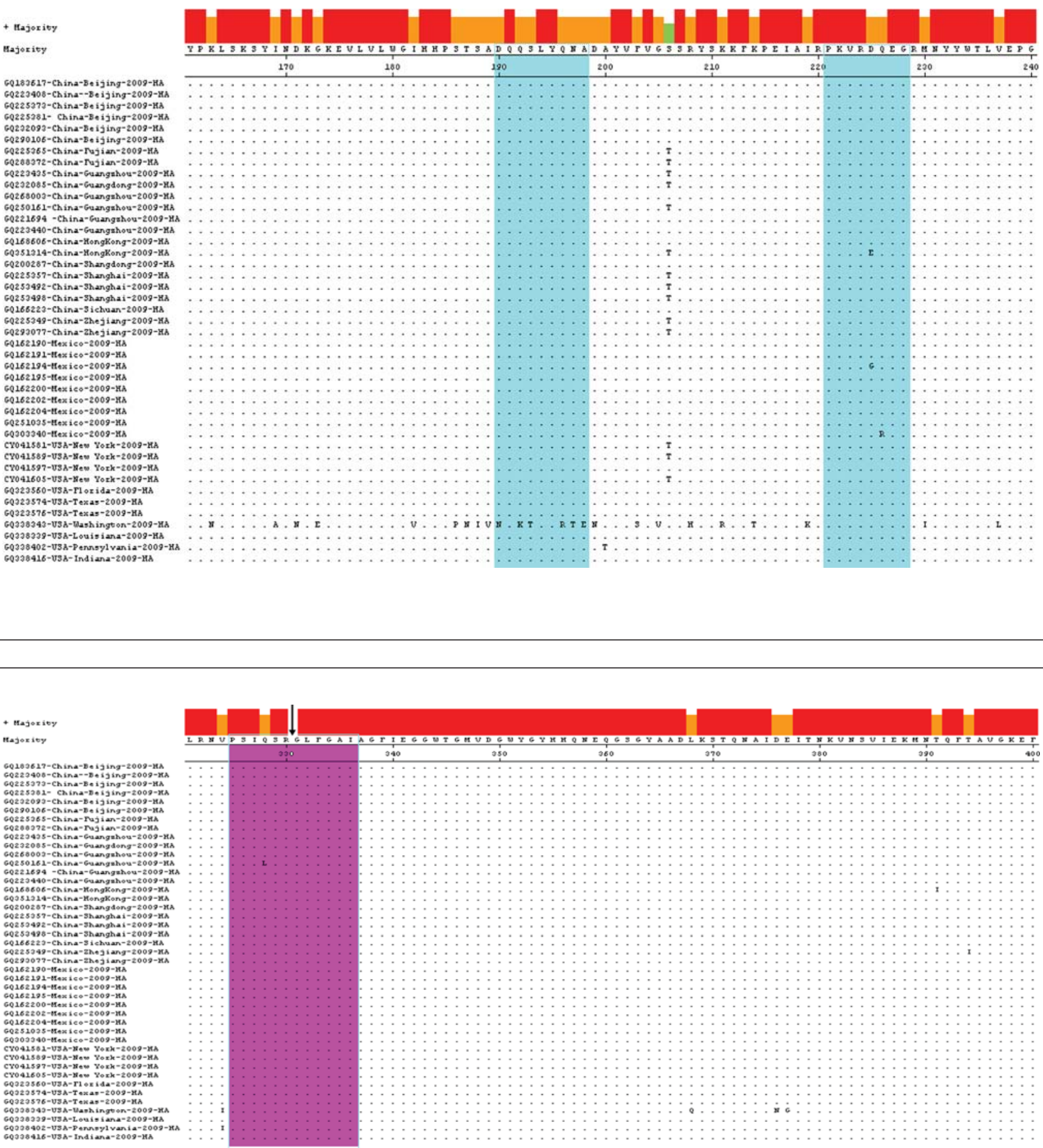

1 


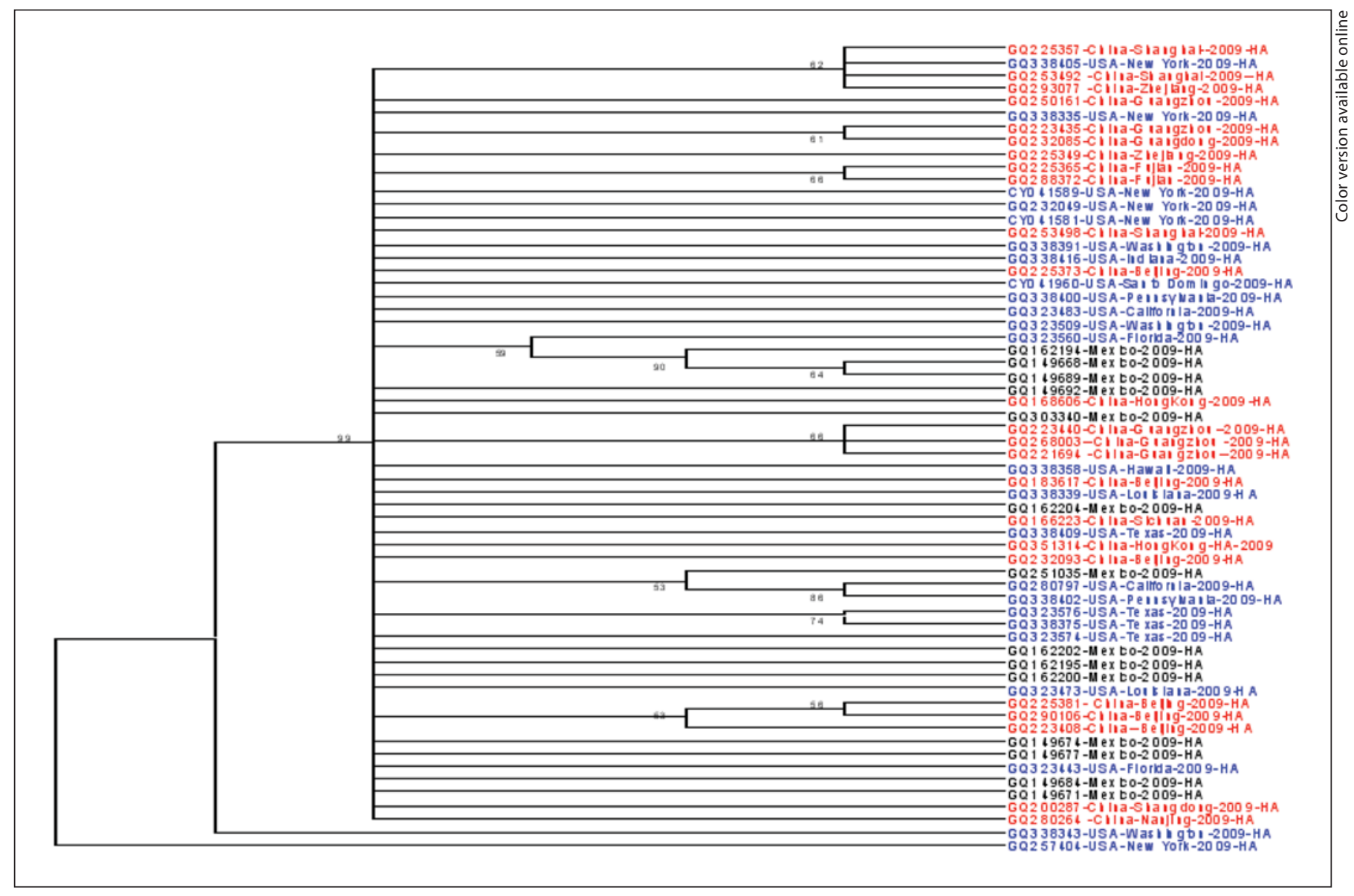

Fig. 2. Phylogenetic tree of H1N1 influenza HA genes isolated from humans in China, USA and Mexico in 2009. Red, blue, and black text represents the HA gene of H1N1 virus isolated from China, the USA and Mexico, respectively. The number of branches shows the percentage of the rate of clustering; the higher the number, the more similar the two sequences are. Colors refer to the online version only.

were VTAA, VTAS, VSAS, and VTAA in 1947, 19771996, 1999-2008, and 2009, respectively. But the most evident changes were seen in the 190-198 cycle from 1947 to 2009. Notably, there were some amino acid substitutions in the 221-228 cycle before 1999, but no mutations were observed thereafter.

The cleavage site between HA1 and HA2 and the amino acid residues near it were directly associated with H1N1 pathogenicity. We observed that mutations occurred at only 2 sites, i.e. $326 \mathrm{~S} \rightarrow \mathrm{F}$ and $331 \mathrm{G} \rightarrow \mathrm{S}$ in 1947 and 2006, respectively. The amino acids at these sites remained stable in other years. These data revealed that there were no highly pathogenic sequences (RXR/ KRGLF). Thus, H1N1 viruses isolated in China have had low pathogenicity over the past $\sim 60$ years.

Evolutionary Characterization of $\mathrm{H} 1 \mathrm{~N} 1$ Hemagglutinin Genes
Comparison of H1N1 HA Gene Sequences Isolated from Humans, Swine, and Birds in China

We analyzed $32 \mathrm{H} 1 \mathrm{~N} 1 \mathrm{HA}$ gene sequences (isolated from 6 human, 22 swine, and 4 avian) and compared their $\mathrm{RB}$, glycosylation, and cleavage sites. The sequences in the first cycle (aa 135-138) in the RB sites were VTAA, VTAA/VSAS/TTVA/VTSA, and VTAA/VSSA/VTAS in humans, swine, and birds, respectively. The sequences in the second cycle (aa 190-198) were DQQSLYQNA, DQQSLYQNA/EQRAIYHTE/DQQTLYQNN/EQQTLYQNT/DQQSLYQNL and EQQSLYQNA/DQRAIYHTE/EQTRLYQNP in humans, swine, and birds, respectively. In the third cycle (aa 221-228) in the RB sites, only sequences at aa 225 and aa 227 changed. At aa 225 , the sequences were $D, G / E / N / D$, and $G$ in humans, swine, and birds, respectively; at aa 227, they were E, A/T/E, and 
Table 2. Amino acid mutations at antigenic sites of H1N1 influenza HA protein isolated from China from 1947 to 2009

\begin{tabular}{|c|c|c|c|c|c|c|c|c|c|c|c|}
\hline \multirow[t]{2}{*}{ Site } & & \multicolumn{10}{|l|}{ Year } \\
\hline & & 1947 & 1977 & 1985 & 1996 & 1999 & 2002 & 2005 & 2006 & 2008 & 2009 \\
\hline \multirow{5}{*}{$\begin{array}{l}\text { Glycosylation } \\
\text { site }\end{array}$} & 14 (NST) & - & - & - & - & - & - & - & - & - & - \\
\hline & 26 (NVTV) & - & - & - & - & NVAV & - & - & - & - & - \\
\hline & 90 (NGTC) & NGAC & - & - & - & - & - & - & - & - & - \\
\hline & 484 (NGTY) & - & - & - & - & - & - & - & - & - & - \\
\hline & 543 (NGSL) & - & - & - & - & - & - & - & - & - & - \\
\hline \multirow[t]{3}{*}{ RB site } & $\begin{array}{l}\text { 135-138 } \\
\text { (VTAA) } \\
\text { (VTAA) }\end{array}$ & VTAA & VTAS & VTAS & VTAS & VSAS & VSAS & VSAS & VSAS & VSAS & VTAA \\
\hline & (PKVRDQEG) & RGQ & RGQ & RGQ & RGQ & KDQ & & & & & \\
\hline & & $\mathrm{AG}$ & $\mathrm{AG}$ & $\mathrm{AG}$ & EG & $\mathrm{HG}$ & & & & & \\
\hline \multirow[t]{3}{*}{ Cleavage site } & $325-333$ & PFI & - & - & - & - & - & - & PSI & - & - \\
\hline & & QSR & & & & & & & QSR & & \\
\hline & (PSIQSRGLF) & XLF & & & & & & & SLF & & \\
\hline
\end{tabular}

- = No mutations occurred within the aa sequence; RB site = receptor-binding site.

A/E/S in humans, swine, and birds, respectively. At aa 226 and aa 228, the amino acids were Q and G, respectively, in all 3 species. The glycosylation site at aa 279 was absent in the HA of some of the swine and avian H1N1 isolates. The glycosylation site at aa 290 was absent only in the HA of swine H1N1 isolates; this site was present in human and avian $\mathrm{H} 1 \mathrm{~N} 1$ isolates. The other glycosylation and cleavage sites remained stable in the 3 species, with the exception of isolate EU874899 (fig. 4).

Analysis of the phylogenetic tree of the H1N1 HA isolated from humans, swine, and birds indicated that the human strains aggregated together and differed completely from the swine and avian strains. There were 3 branches of swine strains, and the avian strains were closer to one of these branches (fig. 5).

\section{Prediction of Three-Dimensional Structure of H1N1 \\ HA of Wild and Mutated Strains}

The most common mutation site of $\mathrm{HA}$ of $\mathrm{H} 1 \mathrm{~N} 1$ isolated in China in 2009 was aa $206(\mathrm{~S} \rightarrow \mathrm{T})$. Here, we compared the three-dimensional structure of a wild-type strain (GQ183617) and a mutant strain (GQ225365, with aa $206 \mathrm{~S} \rightarrow \mathrm{T}$ ) isolated from humans. These 2 strains had the same structure in HA1 and HA2. This result indicated that this single mutation (aa $206 \mathrm{~S} \rightarrow \mathrm{T}$ ) did not change the spiral structures and the pathogenicity of the virus. In contrast, when the mutation occurred in the cleavage sites, the 2 sequences (the strain with mutated cleavage sites, EU874899 and GQ225365 with no mutation in cleavage sites) had clearly differences in their structures. HA2 of the mutant had more $\alpha$-helices (blue spiral structures) than the wild-type strain. The most evident differences were seen at and around the glycosylation site at aa 484 . However, there were no differences near the $3 \mathrm{RB}$ sites between the 2 strains (fig. 6).

\section{Discussion}

The H1N1 influenza genome has 8 gene segments, namely PB1, PB2, PA, HA, NP, NA, M, and NS, which encode at least ten kinds of protein antigens. American experts have speculated that the novel virus responsible for the 2009 influenza pandemic has 6 gene fragments 


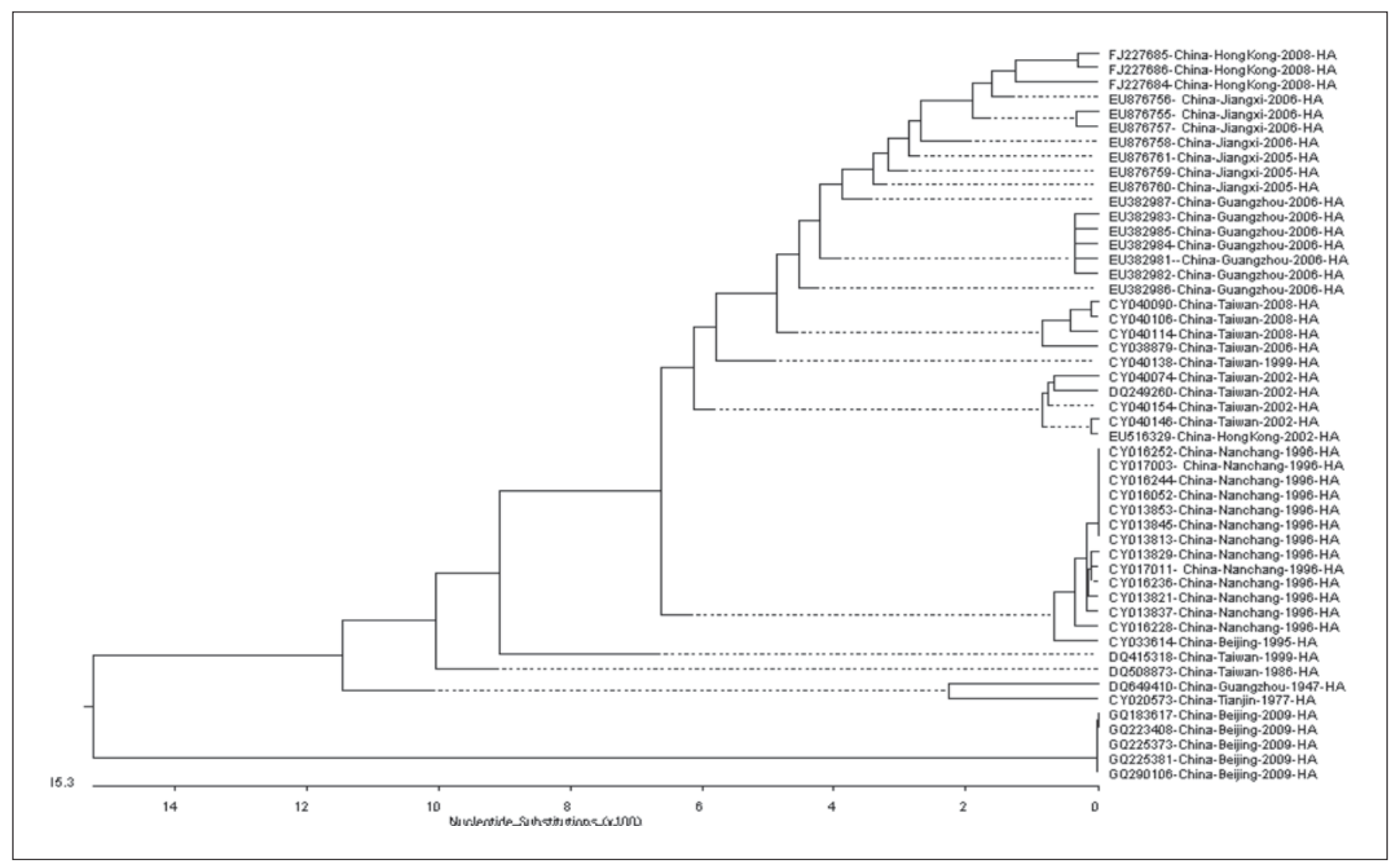

Fig. 3. Phylogenetic tree of H1N1 influenza HA genes isolated in China from 1947 to 2009. The tree was constructed by the Jotun Hein method. The horizontal lengths of the branches are proportional to the sequence differences. Vertical lines represent evolutionary spacing.

reassorted from swine, avian, and human gene fragments [14-17]. There are 2 major membrane antigens in influenza virus: $\mathrm{HA}$ and NA. HA is encoded by gene segment 4 and it will be cleaved into HA1 and HA2 subunits by trypsin or furin-like proteases. Mature HA is homotrimeric and not only mediates the early steps of viral replication, receptor binding, and membrane fusion, but also is directly associated with host susceptibility and immune response $[18,19]$. HA gene variation determines the antigenic characteristics and influenza epidemics features. For the prevention and treatment of $\mathrm{H} 1 \mathrm{~N} 1$, it is very important to conduct research on HA gene mutations and understand its evolution at the molecular level [20]. Here, we analyzed the Chinese H1N1 influenza HA gene from the geographical, time longitudinal and species aspects.

First, our results revealed that the 2009 global H1N1 influenza pandemic originated from the same virus because there were higher identity and closer evolution in strains from China, Mexico and the USA. It was well known that the HA gene has 4 important types of sites, including $4 \mathrm{AD}$ sites, 8 glycosylation sites, $3 \mathrm{RB}$ sites and 1 cleavage site which were associated with pathogenicity and conducive to virus proliferation and replication [21, 22]. Here, there were 15 amino acid substitutions in AD sites from 2009 Chinese H1N1, the most common one being aa $206(\mathrm{~S} \rightarrow \mathrm{T})$ which cannot obviously change the predicated three-dimensional structures of HA protein. The mutation rate was $35.71 \%$ (15/42), lower than the other studies (42.2\%) [23]. Furthermore, HA1 has a higher mutation rate than $\mathrm{HA} 2$. AD sites mutations may change the ability of interacting with neutralizing antibodies [24, $25]$. But there was no evidence it contacted with virulence-associated variation or host changes [4]. In contrast, there were no consequent basic amino acids changes in the all glycosylation and RB and cleavage sites. Thus, $2009 \mathrm{H} 1 \mathrm{~N} 1$ isolates from China had high affinity and low pathogenicity to humans. 
ar852271-5wine-Gaangdong-2001-His 90 100 110 120 120 140 150

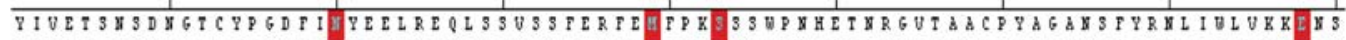

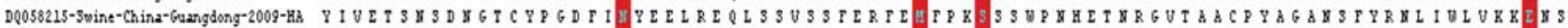

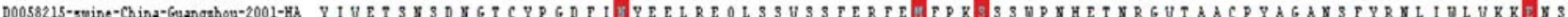

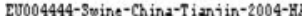
Ev004452-3wine-China-Henan-2006-H3 EUS02884-swine-China-Shanghai-2005-HA EUS02885-"-9wine-China-3hanghai-2005-Hhs IJ415610-Swine-China-2hejiang-2007-HA TN789832-Swine-China-3hanghai-2005-HA GQ229277-3wine-Hongk ong-1993-13s 6Q229285-3wine-Hongk ong-2001-Hh GQ229293-3wint-Hongkong-2001- $\mathrm{H3}$ G0229301-3wine-Hongkong-2009-113 60229325-5wine-Hongkong-2007-H/3 GQ229341-3wine-Hongkong-2009-HA G0229357-3wine-Hongkong-2001-H/ I IJJ44482-Swine-Hongkong-1993-Hih-P INT45451-3wine-Hongkong-1993-HA-7 I $3045452-3$ wine-Hongk ong-1994-H/3-P INU45020-3wine-Hongk ong-1993-HA-P

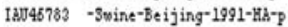

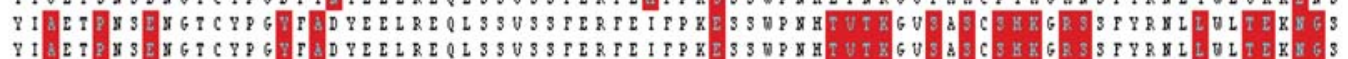

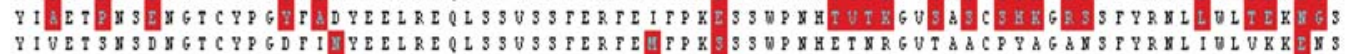

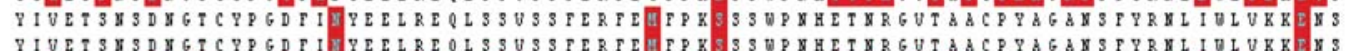
YIFET3 S

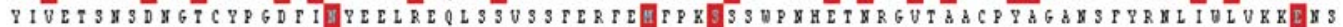

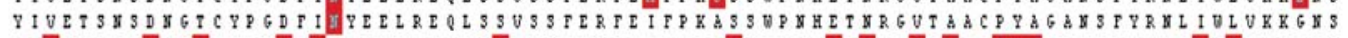
YI IET 3 I 3

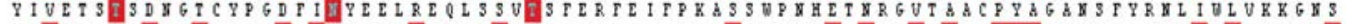

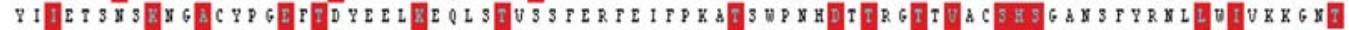

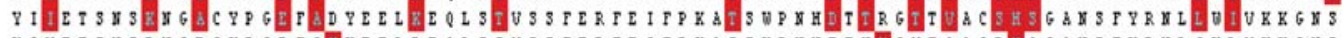

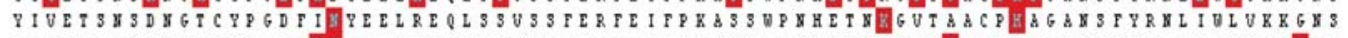

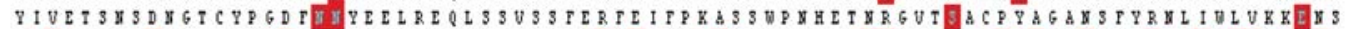

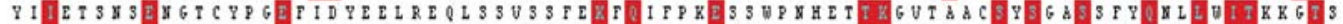

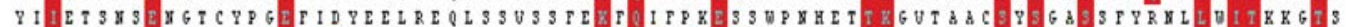

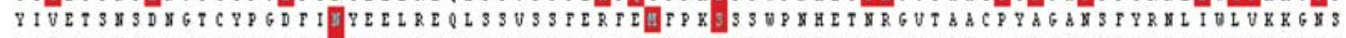

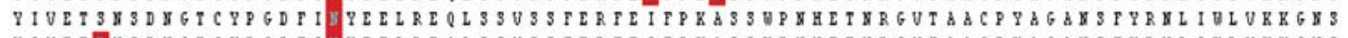

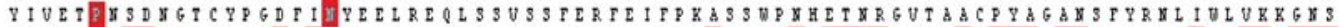
AV180450-0uail-China-Xinching-17i-2000 IIt87489 13046021-goose-China-liongkong-lih-1976 IAW46782-chicken-China-Hongkong-His-1976 GQ183617-China-Beijing-2009-HA GQ223408-China-Beijing-2009-173 GQ225373-China-Beijing-2009-HIB GQ225373-China-Beijing-2009-HIs
G0225381- China-Beijing-2009-13/ GQ232093-China-Beijing-2009-HBs

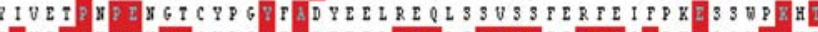
Y

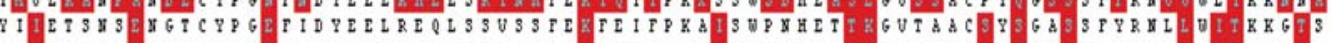

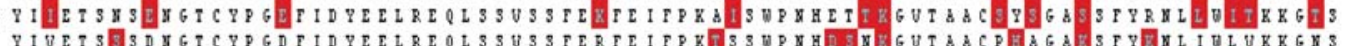

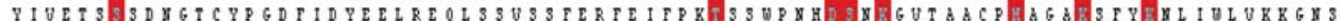

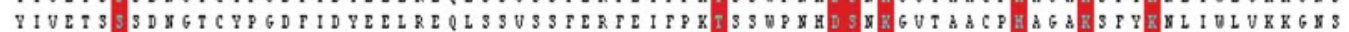

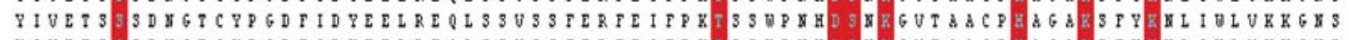

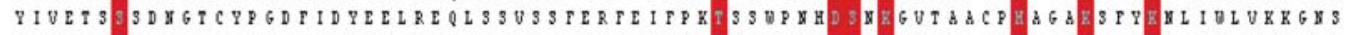

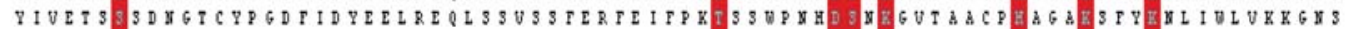

+ Hajority

Hajority

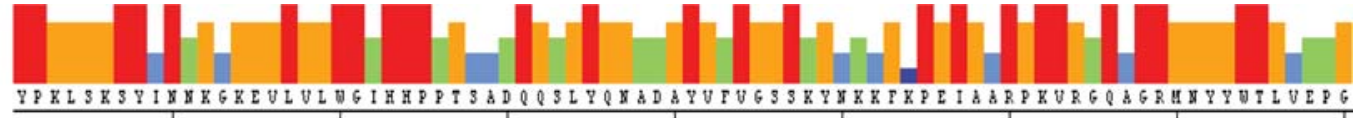

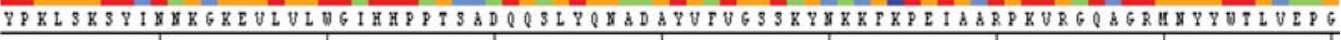

170

180

190

200

210

220

aY852271-3vine-Guangdong-2001-HB

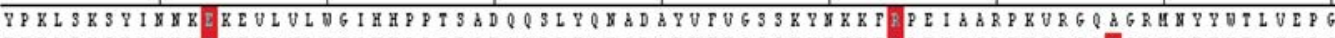

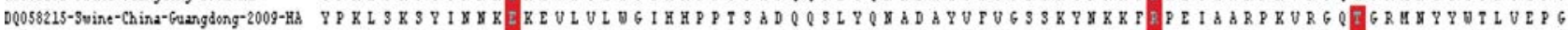

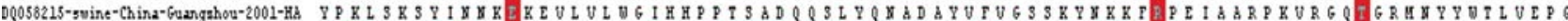

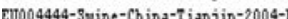
Ev004452-3vine-China-Henan-2006-HA EUS02884-swine-China-Sharghai -2005 - BA CUS02885--gvine-China-Shanghai-2005-HA TJ415610-3vine-China-2hejiang-2007-HA TN789832-3vine-China-Shanghai-2005-HA 6Q229277-5vine-Hongk ong-1993-HA GQ229285-3vine-Hongkong-2001-HB GQ229293-3vine-Hongk ong-2001- 138 GQ229301-Svine-Hilongkong-2009-H3 GQ229325-Svine-Hongkong-2007-HB GQ229341-3vine-Hilongk ong-2009-138 G0229357-3vine-Hongkong-2001-kis ILV44482-3vine-Hongkong-1993-HkI3V45451-3vine-Hongkong-1993-B3-?

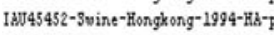
IIJ45020-3vine-Hongkong-1993-Ha-p IA046783 -3vine-Beijing-1991-Hk-p

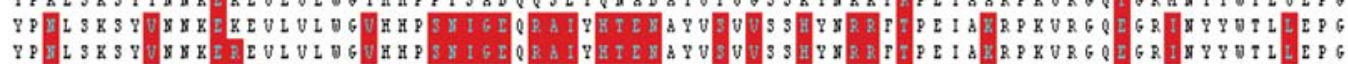

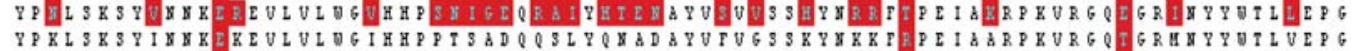

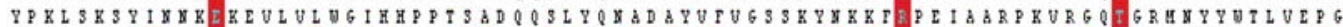

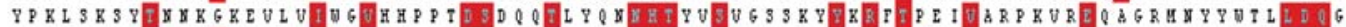

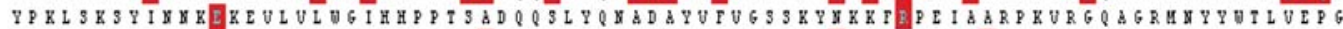

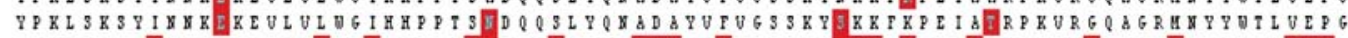

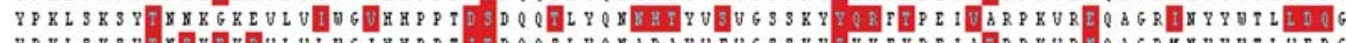

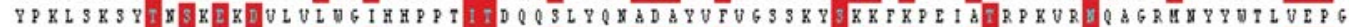

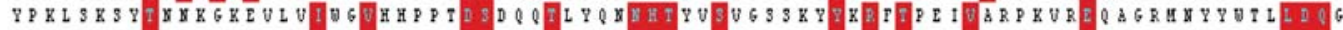

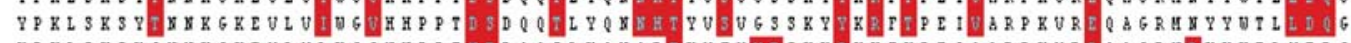

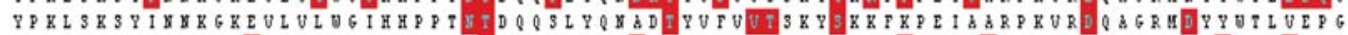

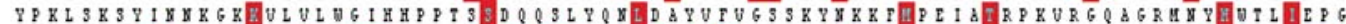

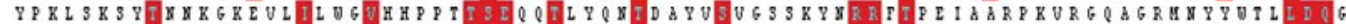

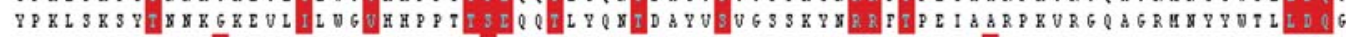

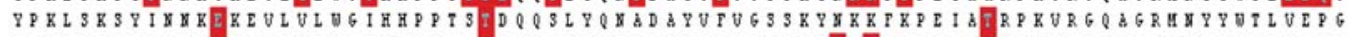

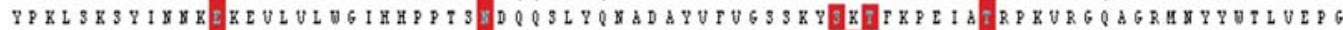

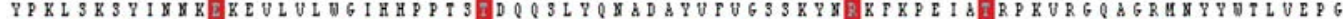

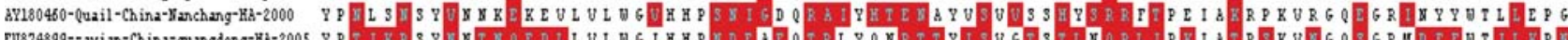

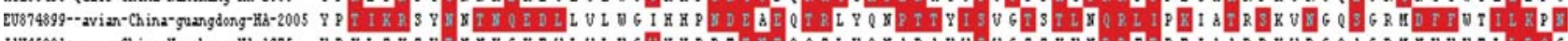

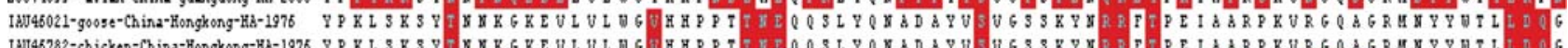

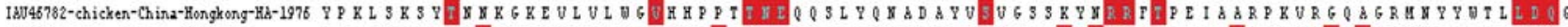
GQ183617-China-Beijing-2009-HB 6Q223408-China--Beijing-2009-1B GQ225373-China-Beijing-2009-BA 60225381- China-Beijing-2009-HB GQ232093-China-Beijing-2009-HB

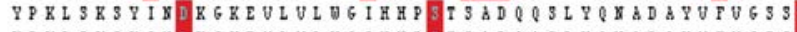

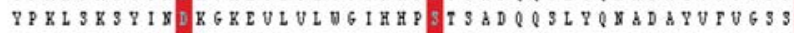

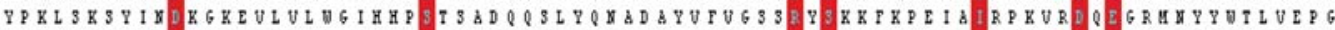

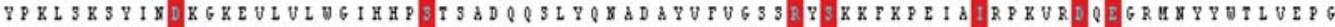
6Q290106-China-Beijing-2009-Hb 
+ Hajority

Hajority

ar852271-Swine-Gaangdong-2001-H3

DQ058215-Swine-China-Guargdong-2009DQ058215-swine-China-Guangahou-2001-His Ev004444-Swine-China- 7 i $2 \pi j$ in-2004-His Ev004452-3wine-China-Henan-2006-HAs EU502884-9wine-China-Shanghai-2005-His EUS02885--swine-China-Shanghai-2005-HI TJ415610-Swine-China-2hejiang-2007-His FJ789832-3wine-China-Sharghai-2005-HA 60229277-3wine-hongk ong-1993-His G0229285-8wine-Hongk ong-2001-H3 60229293-3wine-Hongkong-2001-H/ GQ229301-3wine-Hongkong-2009-HB 60229325-3wine-Hongkong-2007-His G0229341-3wine-Hongkong-2009-H3 60229357-3wine-Hongkong-2001I 3 JJ44482-Swine-Hongkong-1993-HisI IIJ45451-3wine-Hongkong-1993-HA-p I $3045452-3$ wine-Hongkong-1994-His-p I IJT45020-3wine-Hongkong-1993-H13-p IJJ45783 - Swine-Beijing-1991BV180460-Quai 1 -China-II anchang-HB-2000 Ev874899--avian-China-guargdong-HA-2005 D IAJ46021-goose-China-Hongk ong-HB-1976 IWJ45782-chicken-China-Hongkong-HA-1976 60183617-China-Beijing-2009-HA GQ223408-China--Beijing-2009-BA 60225373-China-Beijing-2009-His GQ225381- China-Beijing-2009-H GQ232093-China-Beijing-2009-HA GQ290106-China-Beijing-2009-HA

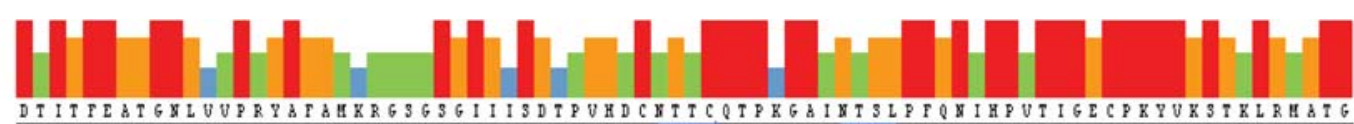

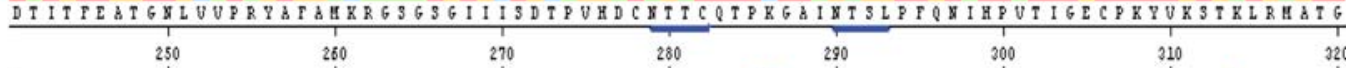

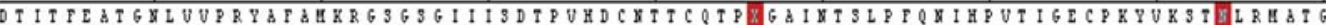

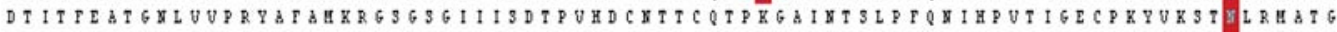

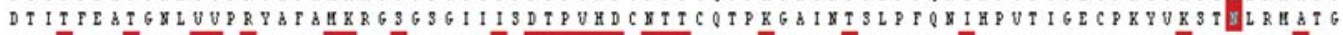

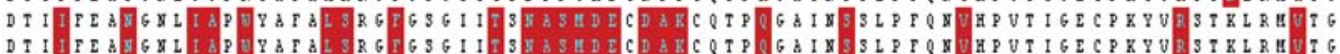

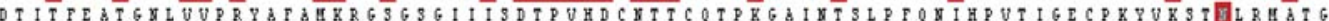

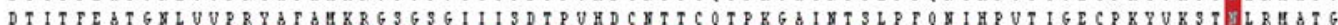

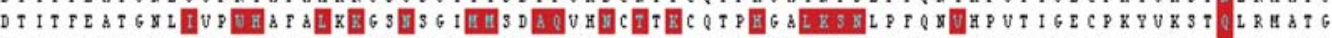

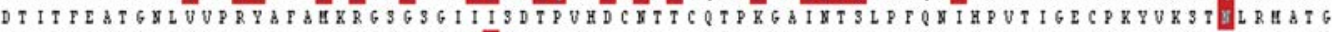

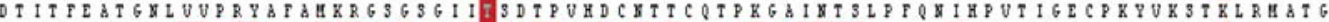

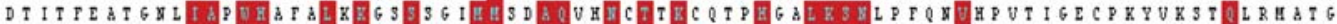

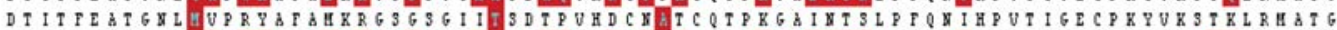

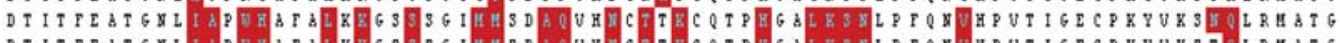

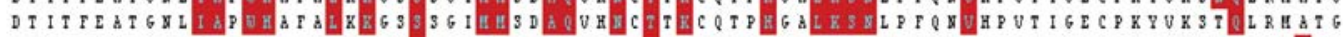

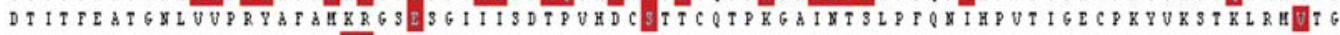

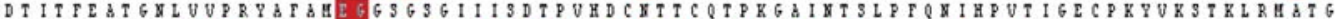

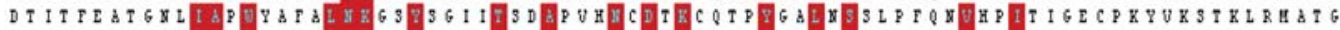

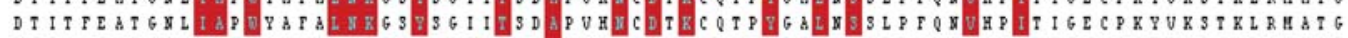

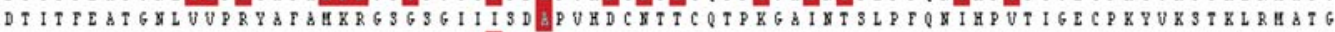

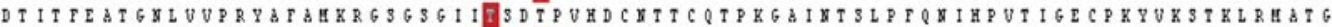

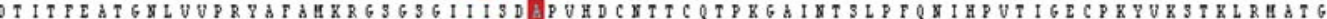

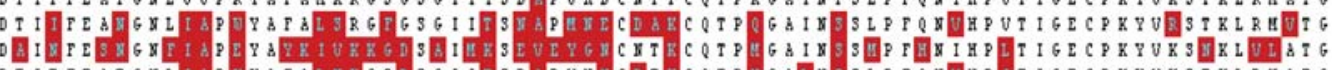

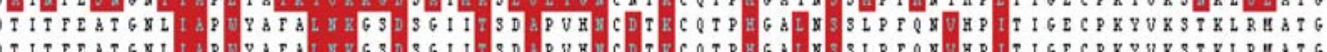

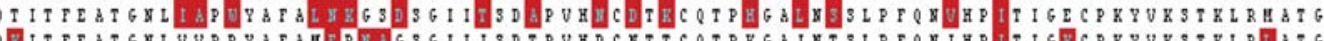

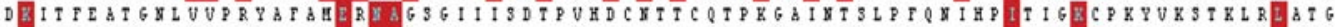
DIT

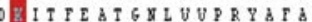

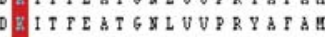
DITEEATGSLUVPRYATABEREUGSGT 1
1 $T$
$T$

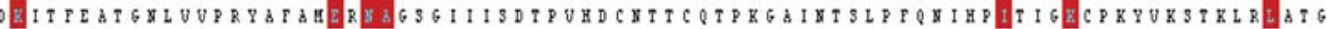

\section{+ Hajority}

llajority

aY852271-Swine-Guangdong-2001-HB DQ058215-3wine-China-Guangdong-2009-H/A DQ058215-swine-China-Geargehou-2001-HA Ev004444-Swine-China-T ianj in-2004-H CU004452-Swine-China-Henan-2006-HA EUS02884-gvine-China-Shanghai-2005-HA Ev502885--swine-China-Sharghai-2005-HA FN415610-5wine-China-2hejiarg-2007-HA TJ789832-9wine-China-Shanghai-205-
GQ229277-3wine-Hongkong-1993-Hs G0229285-Swine-Hongkong-2001-H. GQ229293-3wine-Hongk ong-2001-H. GQ229301-5wine-Hongkong-2009-H G0229325-3wine-Hongkong-2007-H, GQ229241-3wine-Hongk ong-2009-HA G0229357-3 wine-Hongkong-2001I 12044482-3wine-Hongk ong-1992-HA1AN7545452-5wine-Hongk ong-1993-HA-

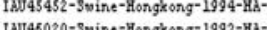

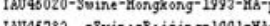
13046785 - Swine-Deijing-1991- Hh-p

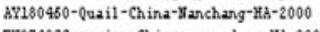
CU874899-- avian-China-guangdong-HA-2005
IWJ45021-goose-China-Hongkong-HB-1976 1AJ45021-goose-China-Hongkong-His-1976 IWW45782-chicken-China-Hongkong-His-1976 i R G0183617-China-Bei jing-2009-HA GQ223408-China--Be ij ing-2009-H 6Q225373-China-Beijing-2009-H, GQ225081- China-Beijing-2009- Ho G0232093-China-Beijing-2009-HB GQ290106-China-Beijing-2009-His

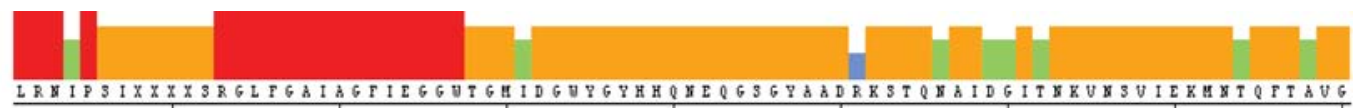

(900

340 320 380

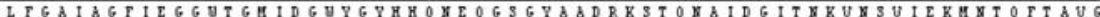

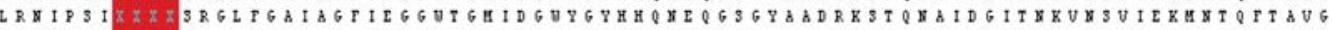

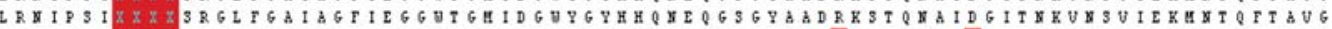

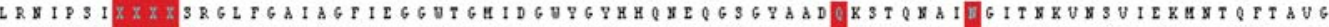

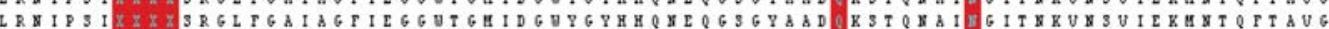

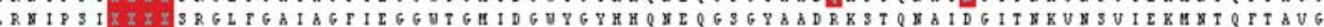

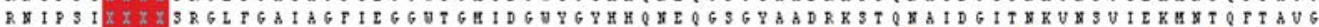

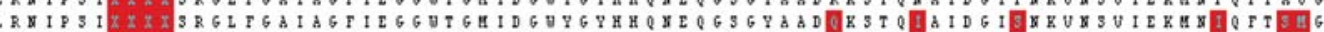

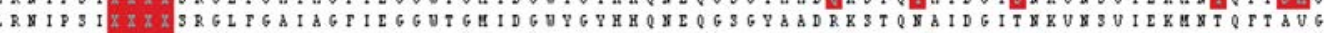

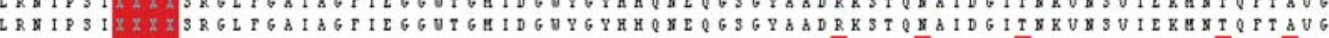

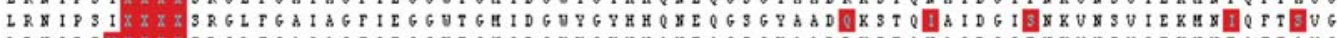

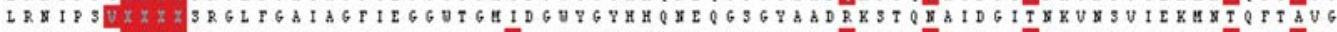

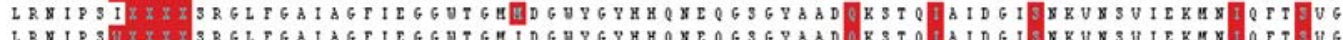

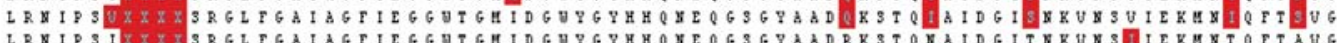

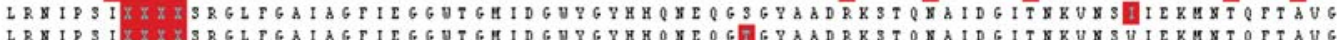
L R. I I I 3 I I L R I I I I P S I

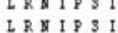

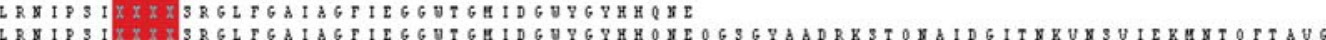
RI LR:B DX

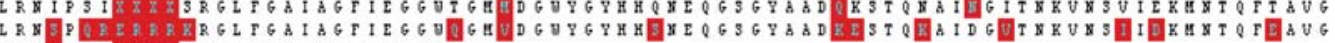

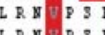
LRX RA P3T.

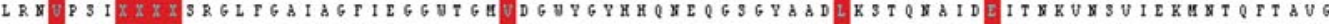

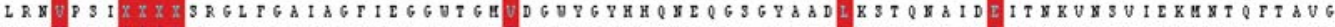

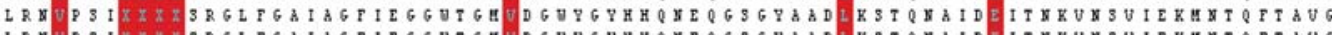

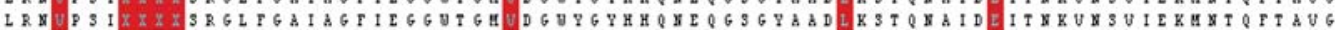

Fig. 4. Comparison of H1N1 influenza HA amino acid from human, swine and avian isolates in China. Blue color '-', potential glycosylation; red color, the amino sequence was different from others. Mutation frequencies are represented by the colored blocks at the top of the figures; hotter colors and higher blocks represent sequences that were conserved, and cooler colors and shorter blocks represent areas with more divergence. The amino acid names and their positions are shown on the second and third line. The strain names downloaded from GenBank are shown on the left. Colors refer to the online version only. 


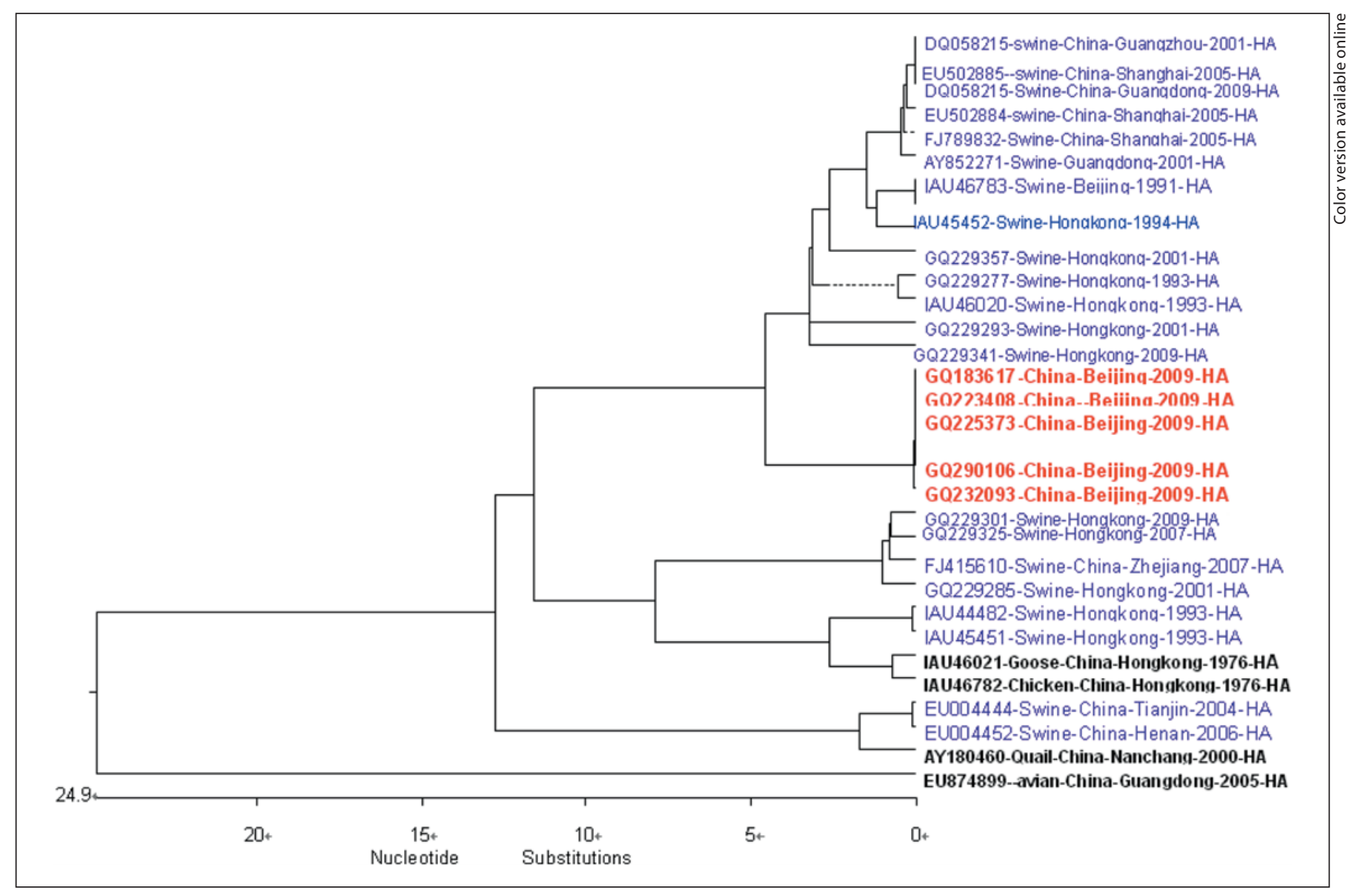

Fig. 5. Phylogenetic tree of H1N1 influenza HA genes from human, swine and avian isolates in China. Red, H1N1 strains from human isolates; blue, H1N1 strains from swine isolates; black, H1N1 strains from avian isolates. The tree was constructed by the
Jotun Hein method. The horizontal lengths of the branches are proportional to the sequence differences, and vertical lines represent evolutionary spacing. Colors refer to the online version only.
Second, $50 \mathrm{HA}$ genes were compared from 1947 to 2009. The phylogenetic tree showed that the sequences clustered on the basis of the isolation year. It also revealed that the HA genes changed considerably with year. Surprisingly, the 2009 HA genes were antigenically distinct from the 2008 strain. This finding provided two insights: (1) the $2009 \mathrm{H} 1 \mathrm{~N} 1$ virus did not originate from previous strains and (2) the population infected with 1947-2008 strains did not provide protection against novel H1N1 virus [2]. It was known that $\mathrm{HA}$ has 8 glycosylation sites, including $6 \mathrm{~N}$ residues in HA1 (aa 13 , aa 14 , aa 26 , aa 90 , aa 279 , and aa 290) and $2 \mathrm{~N}$ residues in HA2 (aa 484 and aa 543). We found that only 2 (aa 279 and aa 290) of these sites have undergone considerable changes over the past 60 years. The other sites have remained stable. The mutations of HA glycosylations near cleavage sites mainly di- rectly affect HA cleavage, which associated with epidemic strength and range [26]. Although glycosylation sites were not necessary for the survival of influenza virus, they played an important role in determining some properties of these viruses. Vasiliy [see 27,28$]$ reported that a negatively charged glycosylation site near HA RB sites affect HA receptor binding, leading to reduced influenza virus dependence on NA which was the target of antiinfluenza drug failure. Furthermore, the $3 \mathrm{RB}$ sites underwent considerable changes with time. However, the amino acids were $\mathrm{Q}$ and $\mathrm{G}$ at aa 226 and aa 228, respectively, which indicated a high affinity to the $S A \alpha 2,6 \mathrm{Gal}$ receptor; thus, the virus host range in humans has not changed in the past 60 years. Only a single substitution was observed at the cleavage sites in 1947 and 2006. The HA cleavage site sequence was PSIQSRGLFGAI, which 


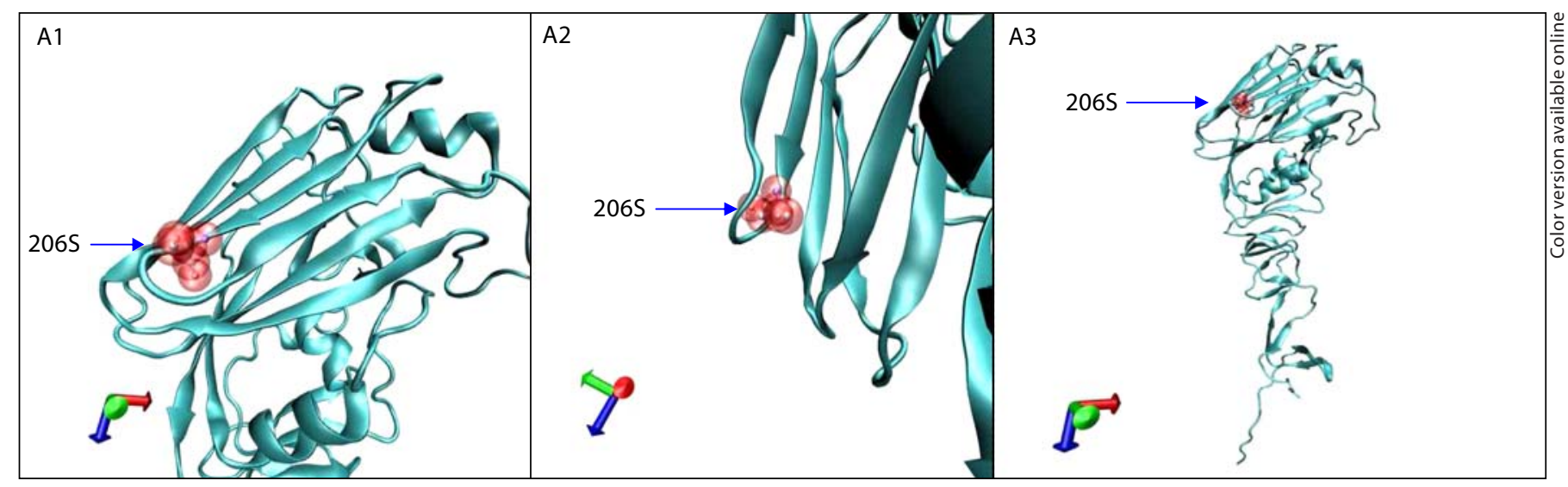

Wild-type strain (GQ183617)

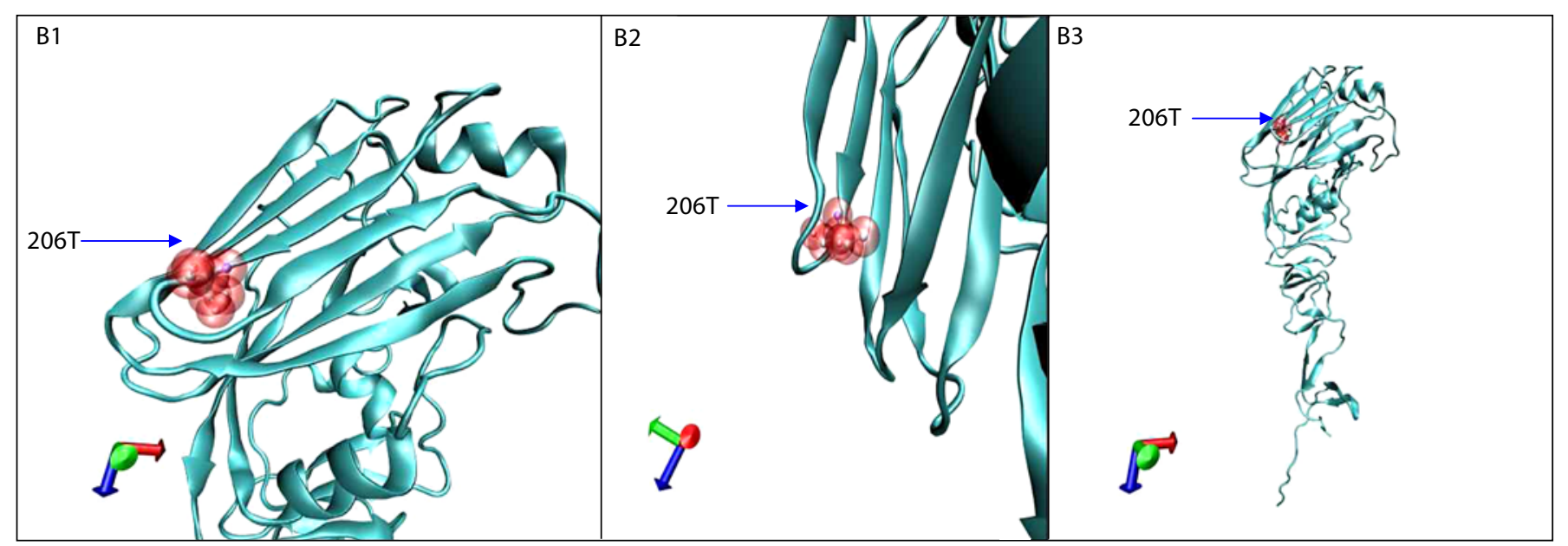

206S $\rightarrow$ T mutant (GQ225365)

Fig. 6. Predictions of the three-dimensional structure of the HA proteins from wild-type and mutated strains. Red and silver colors represent aa 206 and all other amino acids (except 206), respectively, in panels A1-A3, and B1-B3. Red, yellow and green represent $\mathrm{RB}$ sites, glycosylation sites and cleavage sites, respec- tively, in panels $\mathrm{H} 1, \mathrm{H} 2$ and L1, L2. In these panels, blue color represents other amino acids that do not correspond to RB sites, glycosylation sites or cleavage sites. Colors refer to the online version only. (Figure 6 continues on the next page.) represented with low virulence, but not a highly pathogenic sequence (RXR/KRGLF) in the past 60 years. Specific proteases and certain bacteria can identify and crack the cleavage site, causing local respiratory or digestive tract infections [29-34]. So, Chinese H1N1 strains have had low pathogenicity and relatively conservation except 2 glycosylation and $3 \mathrm{RB}$ sites over the past 60 years.

Third, 2009 human H1N1 formed an independent branch in the phylogenetic tree, which obviously differed from swine and avian isolates. In addition, there were some differences in the first (135-138 VTAA) and second cycle (190-198 DQQSLYQNA) of the RB sites among 3 species. This result revealed that $2 \mathrm{RB}$ sites possessed host specificity. In contrast, the third cycle (221-228 PKVRDQEG) remained the same in the 3 species. Only 2 glycosylation sites (aa 279 and aa 290) have changed in all species. We compared the three-dimensional structure of HA in a wild-type strain (GQ225365) and a mutated strain (EU874899). It showed that they were very distinctive between the 2 strains. The protein structure of the mutant in cleavage sites facilitated its binding with receptors of more systems. It was reported that a single amino acid mutation in cleavage sites, such as $\mathrm{L} \rightarrow \mathrm{Q}$ at aa 226 , changes $R B$ specificity from $S A \alpha 2,3 \mathrm{Gal}$ to $\mathrm{SA} \alpha 2,6 \mathrm{Gal}$, thus transforming the virus host range. 


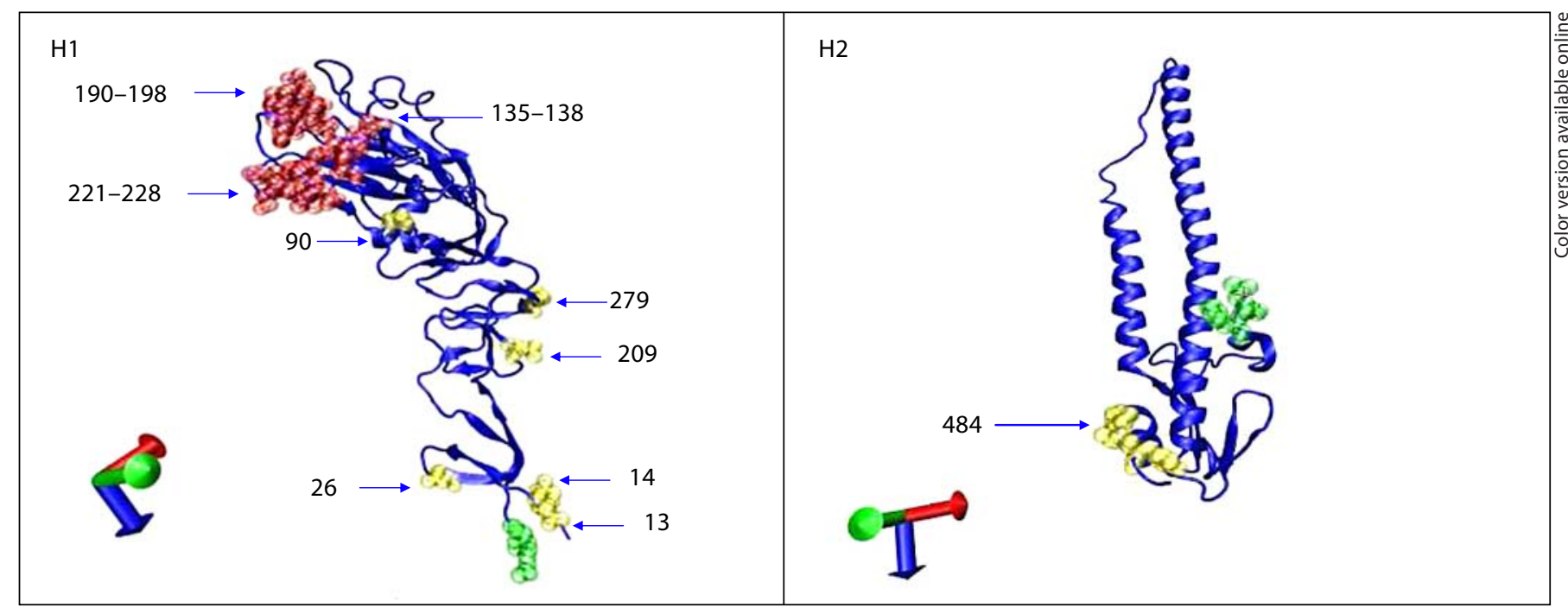

EU874899-AVIAN-H1N1-Guangzhou-HA1

EU874899-AVIAN-H1N1-Guangzhou-HA2

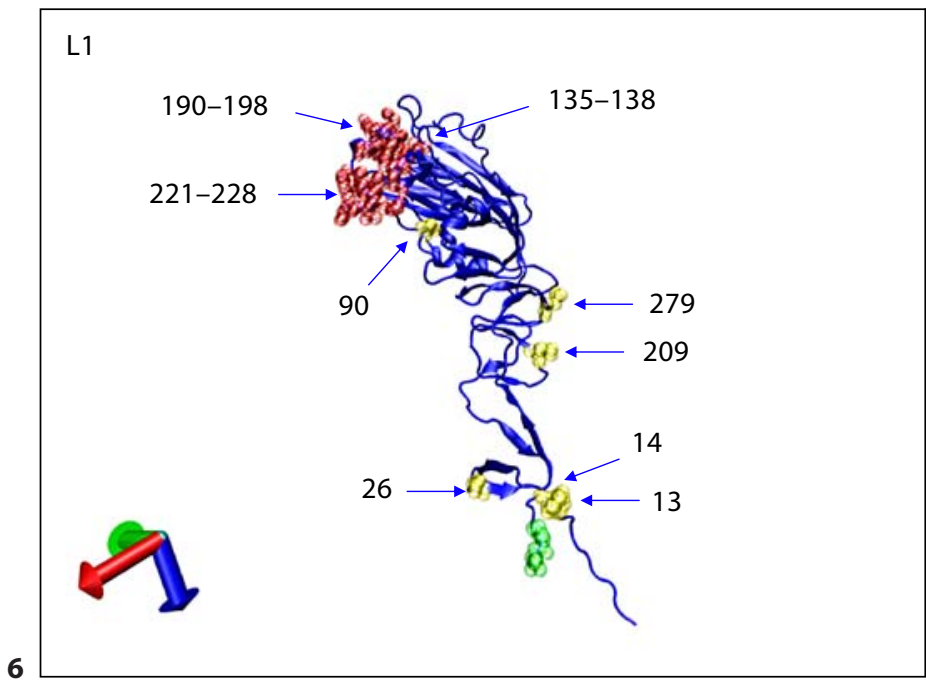

GQ225365-human-H1N1-Fujian-HA1
L2

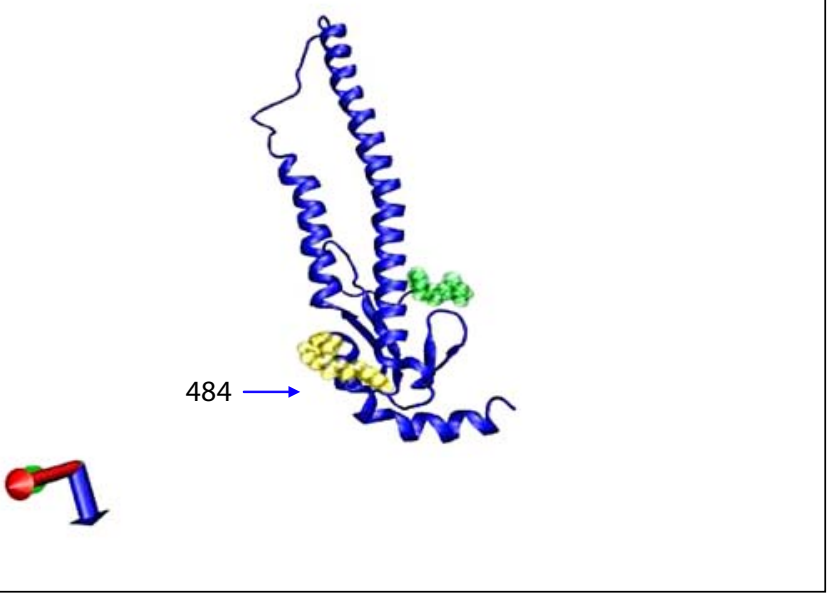

GQ225365-human-H1N1-Fujian-HA2
In conclusion, the evolutionary features of Chinese H1N1 were the following: (1) the 2009 virus was the same as in other countries around the world, with low pathogenicity and high affinity to humans; (2) over the past $\sim 60$ years, the glycosylation sites have remained highly conserved, with the exception of aa 279 and aa 290, which were associated with epidemic strength and range and host specificity; (3) the RB sites changed with year and species, but it was still unknown whether it can enhance the virulence or epidemic range, and (4) the mutation in the cleavage sites will affect the spatial structure, related to the virulence and host of the virus. This study was very important to predict the H1N1 influenza in the world. Although H1N1 influenza appeared in the low-epidemic period, it will become unknown in the future. Therefore, it is necessary to strengthen virological surveillance, paying more attention to the molecular evolution of key sites such as cleavage sites and glycosylation sites located in aa 279 and aa 290.

\section{Acknowledgements}

This work was supported by the National Natural Science Foundation of China (30901285), Mega-Projects of Science Research for the 11th and 12th Five-Year Plan of China (2009ZX10004-901, 2009BAI83B01 and 2011ZX10004-901) and by the National Key Basic Research and Development Program of China (9732007BC109103). 


\section{References}

$>1$ Fouchier RA, Munster V, Wallensten A, Bestebroer TM, Herfst S, Smith D, Rimmelzwaan GF, Olsen B, Osterhaus AD: Characterization of a novel influenza A virus HA subtype (H16) obtained from black headed gulls. J Virol 2005;79:2814-2822.

$>2$ Novel Swine-Origin Influenza A (H1N1) Virus Investigation Team: Emergence of a novel swine-origin influenza A (H1N1) virus in humans. N Engl J Med 2009;360:2605-2615.

$>3$ Vincent AL, Swenson SL, Lager KM, Gauger PC, Loiacono C, Zhang Y: Characterization of an influenza A virus isolated from pigs during an outbreak of respiratory disease in swine and people during a county fair in the United States. Vet Microbiol 2009;137:51-59.

4 Smith GJ, Vijaykrishna D, Bahl J, Lycett SJ, Worobey M, Pybus OG, Ma SK, Cheung CL, Raghwani J, Bhatt S, Peiris JS, Guan Y, Rambaut A: Origins and evolutionary genomics of the 2009 swine-origin H1N1 influenza A epidemic. Nature 2009;459:1122-1125.

5 World Health Organization: Available from: http://www.who.int/csr/don/2010_08_06/ en/index.html.

6 Ministry of Health of the People's Republic of China. Available from: http://www. chinacdc.net.cn.

$>7$ Gallaher WR: Towards a sane and rational approach to management of influenza H1N1. Virol J 2009;6:51-54.

$>8$ Kelley LA, MacCallum RM, Sternberg MJ: Enhanced genome annotation using structural profiles in the program 3D-PSSM. J Mol Biol 2000;299:499-520.

$\checkmark 9$ Karplus K, Barrett C, Hughey R: Hidden Markov models for detecting remote protein homologies. Bioinformatics 1998; 14:846856.

10 Marti-Renom, MA, Stuart AC, Fiser A: Comparative protein structure modeling of genes and genomes. Annu Rev Biophys Biomol Struct 2000;29:291-325.

-11 Maenaka K, Jones EY: MHC superfamily structure and the immune system. Curr Opin Struct Biol 1999;9:745-753.

$\checkmark 12$ Schwede T, Kopp J, Guex N, Peitsch MC; SWISS MODEL: an automated protein homology-modeling server. Nucleic Acids Res 2003;31:3381-3385.
13 William H, Andrew D, Klaus S: VMD: visual molecular dynamics. J Mol Grap 1996;14: 33-38.

14 Gabriel G, Herwig A, Klenk HD: Interaction of polymerase subunit PB2 and NP with importin $\alpha 1$ is a determinant of host range of influenza A virus. PLoS Pathog 2008;4:1114.

15 Qi X, Li X, Rider P, Fan W, Gu H, Xu L, Yang Y, Lu S, Wang H, Liu F: Molecular characterization of highly pathogenic H5N1 avian influenza A viruses isolated from raccoon dogs in China. PLoS One 2009;4:4682-4685.

16 Obenauer JC, Denson J, Mehta PK, Su X, Mukatira S, Finkelstein DB, Xu X, Wang J, Ma J, Fan Y, Rakestraw KM, Webster RG, Hoffmann E, Krauss S, Zheng J, Zhang Z, Naeve CW: Large-scale sequence analysis of avian influenza isolates. Science 2006;311:15761580 .

17 Jackson D, Hossain MJ, Hickman D, Perez DR, Lamb RA: A new influenza virus virulence determinant: the NS1 protein four Cterminal residues modulate pathogenicity. Proc Natl Acad Sci USA 2008;105:43814386

18 Kobasa D, Takada A, Shinya K, Hatta M, Halfmann P, Theriault S, Suzuki $H$, Nishimura H, Mitamura K, Sugaya N, Usui T, Murata T, Maeda Y, Watanabe S, Suresh M, Suzuki T, Suzuki Y, Feldmann H, Kawaoka Y: Enhanced virulence of influenza A viruses with the haemagglutinin of the 1918 pandemic virus. Nature 2004;431:703-707.

19 Matrosovich M, Tuzikov A, Bovin N, Gambaryan A, Klimov A, Castrucci MR, Donatelli I, Kawaoka Y: Early alterations of the receptor-binding properties of $\mathrm{H} 1, \mathrm{H} 2$, and $\mathrm{H} 3$ avian influenza virus HAs after their introduction into mammals. J Virol 2000;74: 8502-8512.

20 Parkin NT, Chiu P, Coelingh K: Genetically engineered live attenuated influenza A virus vaccine candidates. J Virol 1997;71:27722778 .

$\checkmark 21$ Raymond FL, Caton AJ, Cox NJ, Kendal AP, Brownlee GG: The antigenicity and evolution of influenza $\mathrm{Hl}$ haemagglutinin, from 1950 to 1957 and 1977 to 1983 : two pathways from one gene. Virology 1986;148:275-287.

-22 Caton AJ, Brownlee GG, Yewdell JW, Gerhard W: The antigenic structure of the influenza virus A/PR/8/34 HA (HI subtype). Cell 1982;31:417-427.
23 Zhang JH, Xu H, Zhang Y, Zhao X, Guo JF, Lan Y, Shu YL: Evolutionary characterization of HA1 of influenza H1N1 HA gene surveyed in 1981 to 2005 in China. Chin J Virol 2007;24:350-355.

24 Parrish CR, Kawaoka Y: The origins of new pandemic viruses: the acquisition of new host ranges by canine parvovirus and influenza A viruses. Annu Rev Microbiol 2005; 59:553-556.

25 Kehel JJ, Wiley DC: Receptor binding and membrane fusion in virus entry: the influenza HA. Annu Rev Biochem 2000;69:531569.

26 Abe Y, Takashita E, Sugawara K, Matsuzaki Y, Muraki Y, Hongo S: Effect of the addition of oligosaccharides on the biological activities and antigenicity of influenza A/H3N2 virus HA. J Virol 2004;78:9605-9611.

27 Schulze IT: Effects of glycosylation on the properties and functions of influenza virus HA. J Infect Dis 1997;176:S242-S281.

28 Mishin VP, Novikov D, Hayden FG, Gubareva LV: Effect of HA glycoprotein on influenza virus susceptibility to neuraminidase inhibitors. J Virol 2005;79:12416-12424.

29 Luoh SM, McGregor MW, Hinshaw VS: HA mutations related to antigenic variation in H1 swine influenza viruses. J Virol 1992;66: 1066-1073.

30 Gao P, Watanabe S, Ito T, Goto H, Wells K, McGregor M, Cooley AJ, Kawaoka Y: Biological heterogenerity, including systemic replication in mice, of $\mathrm{H} 5 \mathrm{~N} 1$ influenza A virus isolates from humans in Hong Kong. J Virol 1999;73:3184-3189.

-31 Kawaoka Y, Webster RG: Sequence requirements for cleavage activation of influenza virus hemagglutinin expressed in mammalian cells. Proc Natl Acad Sci USA 1988;85:324328 .

32 Klenk HD, Rott R: The molecular biology of influenza virus pathogenicity. Adv Virus Res 1988;34:247-281.

33 Rott R: The pathogenic determinant of influenza virus. Vet Microbiol 1992;33:303-310.

-34 Steinhauer DA: Role for the pathogenicity of influenza virus. Virology 1999;258:1-20. 